\title{
Capacidad de bacterias halófilas para capturar sodio in Vitro y su posible aplicación en bioremediación en suelos salinos-sódicos
}

\author{
Ligia Consuelo Sánchez Leal, MsC. ${ }^{1}$ Heliodoro Arguello Arias, PhD. ${ }^{2}$ \\ ${ }^{1}$ Programa de Biología Aplicada, Universidad Militar Nueva Granada. Docente Universidad Colegio Mayor de Cundinamarca. \\ ${ }^{2}$ Profesor Asociado de Agronomía, Universidad Nacional de Colombia. \\ Correspondencia: Isanchezl@unicolmayor.edu.co
}

Recibido: 24-10-2006 / Aceptado: 24-11-2006

\section{Resumen}

Las prácticas agrícolas inadecuadas han sido la causa del aumento de los suelos salinos-sódicos en todo el planeta. Su recuperación se ha hecho principalmente cambiando el sodio por otro catión, generalmente calcio, remediando en forma mecánica y usando plantas halotolerantes. Aunque estas prácticas controlan en alguna medida el problema, no se ha podido hacer una recuperación efectiva en estos suelos. Este trabajo presenta como alternativa, el uso de bioremediación con bacterias halófilas. El objetivo de la investigación fue evaluar la capacidad de cinco especies de bacterias halófilas para capturar iones sodio in vitro y diseñar una propuesta para su posible aplicación en bioremediación de suelos sódicos y salinos. La captura del sodio se demostró comparando la concentración inicial de la solución de sodio sin inocular y la concentración de la misma con la bacteria inoculada a través de la técnica de espectroscopia de absorción atómica. Las bacterias que demostraron la capacidad de captura de sodio in vitro fueron: Vibrio alginolyticus, Vibrio metschnikovii, Flavimonas oryzihabitans y Agrobacterium tumefasciens. Serratia marcescens no demostró captura. La comprobación de la captura de sodio permitió hacer dos propuestas: diseñar un bioreactor con un consorcio microbiano que incluya las bacterias que capturaron sodio en el experimento y bacterias autóctonas presentes en los suelos salinos y sódicos; utilizar ingeniería genética para implantar el gen de bomba de sodio de la especie con mejor captura, en especies nativas existentes en este tipo de suelos.

Palabras clave: bacterias halófilas, bioremediación, Flavimonas oryzihabitans, suelos salinos, Vibrio alginolyticus, Vibrio metschnikovii.

\begin{abstract}
The inadequate agricultural practices have been the cause of the increase of saline-sodic soils in the entire planet. Its recovery has been done mainly changing sodium by another cation, generally calcium, remedying in mechanical form and using halotolerant plants. Although these practices control the problem to a certain extent, it has not been able to make an effective recovery in these soils. This work displays as an alternative, the use of bioremediation with halophiles bacteria. The objective of the investigation was to evaluate the capacity of five species of halophiles to capture in vitro sodium ions and to design a proposal for its possible application in bioremediation of sodic and saline soils. The capture of sodium was demonstrated by comparing
\end{abstract}


the initial concentration of the sodium solution without inoculating and the concentration of the same one with the bacterium inoculated through the technique of spectroscopy of atomic absorption. The bacteria that demonstrated the capacity to capture sodium in vitro were: Vibrio alginolyticus, Vibrio metschnikovii, Flavimonas oryzihabitans and Agrobacterium tumefasciens. Serratia marcescens did not demonstrate capture. The verification of the sodium capture allowed as to make two proposals: to design a bioreactor with a microbial partnership that includes the bacteria that captured sodium in the experiment and native bacteria in saline and sodic soils and to use genetic engineering to implant the gene of sodium bomb of the species with better capture in existing indigenous flora in this type of grounds.

Key words: bioremediation, Flavimonas oryzihabitans, halophiles bacteria, salt soils, Vibrio alginolyticus, Vibrio metschnikovii.

\section{Introducción}

La presencia de salinidad y sodio en los suelos interfiere en el crecimiento adecuado de la mayoría de los cultivos y por lo tanto constituye uno de los problemas más serios que enfrenta la agricultura sostenible a nivel de todo nuestro planeta. La Organización de las Naciones Unidas para la agricultura y la alimentación FAO y la Organización de las Naciones Unidas para la Educación, la Ciencia y la Cultura UNESCO calculan que el área total de suelos salinos en el mundo es de 397 millones de hectáreas y los suelos sódicos corresponden a 434 millones de hectáreas. Así mismo, estableció que de 230 millones de tierra irrigada, 40 millones de hectáreas son suelos afectados por la salinización (corresponde al 19\%), estas últimas cifras afectadas en menor o mayor grado por la intervención del hombre. $(1,2,3,4)$. En América tropical, (5) se estima que el cuatro por ciento de las tierras son de carácter sódico, salino o ambos. En Colombia, en los valles de los ríos hay presencia de suelos salinos y sódicos. (6).

La recuperación de los suelos sódicos se ha hecho principalmente cambiando el sodio en complejo coloidal por otro catión, aplicando principalmente sales solubles de calcio, sales de calcio con baja solubilidad (cal agrícola); en forma mecánica mezclando la capa superficial con arado y usando plantas halotolerantes; sin embargo, no es fácil ni económico eliminar o disminuir las concentraciones de sodio del suelo. Esta investigación consideró una alternativa diferente de solución al problema de salinización y sodicidad del suelo: la bioremediación, proceso por el cual se pretende recuperar suelos mediante procesos biológicos con microorganismos (7). Trabajos realizados por algunos investigadores quienes valoraron la capacidad de microorganismos como $P$. aeruginosa (8), Bacillus (9), y algunos hongos (10) para remover metales pesados como mercurio, plomo, cadmio, cobalto, entre otros han evidenciado que los microorganismos son capaces de cambiar los iones originales y formar complejos. No se conocen reportes científicos en los cuales se haya considerado la posibilidad de utilizar microorganismos para bioremediar suelos salinos y sódicos.

La hipótesis de esta investigación fue que microorganismos bacterianos con capacidad halófila, es decir que dependen para su supervivencia del sodio, podrían ser utilizados como posibles remediadores de suelos sódicos y salinos. El objetivo fue evaluar la capacidad de microorganismos bacterianos halófilos para capturar iones sodio in vitro y diseñar una propuesta para su posible aplicación en bioremediación de estos suelos. El experimento se desarrolló en dos fases; la primera correspondió a la selección de microorganismos bacterianos con comportamiento halófilo y verificación de crecimiento en soluciones en las cuales se simularon las condiciones de los suelos salinos y sódicos añadiendo sales presentes en este tipo de suelos con diferentes concentraciones. La segunda fase consistió en verificar si las bacterias seleccionadas eran capaces de capturar 
el sodio; esta captura se demostró cuantificando el ión sodio por espectroscopia de absorción atómica en las soluciones preparadas y comparando la concentración del sodio de la solución sin inocular la bacteria con el valor obtenido en la misma solución después de inocular los microorganismos en cada una de las sales en las diferentes concentraciones. Este ensayo fue diseñado por la investigadora quien definió los protocolos correspondientes. Para validar los resultados obtenidos, se aplicó diseño experimental utilizando el Programa estadístico R. Se hizo análisis de varianza y posteriormente se establecieron comparaciones múltiples con prueba de Tukey entre los datos obtenidos, para saber si habían variaciones entre los tratamientos aplicados a cada uno de los microorganismos, si había diferencia entre los resultados arrojados por las cinco bacterias y establecer la bacteria que presentó mejor comportamiento.

Los resultados obtenidos permitieron concluir que aunque todas las bacterias se comportaron como halofilas discretas en la fase inicial, solo Vibrio alginolyticus, y Vibrio metschnikovii capturaron sodio en todas las concentraciones y con todas las sales por los resultados obtenidos en la lectura final. Flavimonas oryzihabitans y Agrobacterium tumefasciens fueron variables, es decir, con algunas sales se observó captura de los iones de sodio, pero con otras, los valores se mantuvieron o elevaron y definitivamente la bacteria que no capturó ningún ión sodio en las sales fue Serratia marcescens.

La comprobación de la captura de sodio por cuatro de las bacterias utilizadas en el experimento es el primer paso para proponer procesos de bioremediación de suelos salinos y sódicos con el uso de microorganismos. Una primera propuesta para la aplicación de bacterias es el diseño de un bioreactor con un consorcio microbiano que incluya las bacterias que capturaron sodio en el experimento y bacterias autóctonas presentes en los suelos salinos y sódicos; esta aplicación se haría a suelos salinos con el fin de evitar que continué su deterioro. La segunda propuesta sería utilizar la ingeniería genética para implantar el gen de bomba de sodio de la especie Vibrio en flora indígena existente en los suelos salinos y sódicos.

\section{Materiales y métodos}

\section{Ensayos preliminares}

Medios de cultivo y pruebas bioquímicas automatizadas de identificación

Los medios de cultivo utilizados en el transporte de las muestras, aislamiento primario y secundario y selección de microorganismos moderadamente halófilos fueron: medio stuart (Merck), agar nutritivo con $1.5 \%$ de cloruro de sodio, agar sangre, agar Mc Conkey, Agar TCBS y agar nutritivo con 3\% de cloruro de sodio (Oxoid). La preparación de los medios de cultivo se hizo de acuerdo con los protocolos de las casas comerciales. El sistema automatizado de pruebas utilizado para la identificación bioquímica fue BBL Crystal ${ }^{\mathrm{TM}}$ Identification System Enteric/Nonfermenter ID Kit. El procedimiento se hizo de acuerdo con las especificaciones técnicas de la casa comercial.

Recolección de la muestra, aislamiento y obtención de cepas bacterianas

El aislamiento de las cepas bacterianas se hizo de agua de mar de diferentes áreas en la isla de San Andrés y de agua superficial del Humedal Cintura de la Cuenca del río San Jorge en Córdoba. Los sitios fueron seleccionados teniendo en cuenta que el hábitat natural de microorganismos moderadamente halófilos es el agua. Las muestras fueron sembradas en Medio de transporte Stuart y llevadas al laboratorio en Bogotá donde se procesaron. Las muestras fueron sembradas en agar nutritivo con cloruro de sodio al $1.5 \%$ y en agar sangre para obtener un aislamiento primario; la incubación fue de 24 horas a $35.5^{\circ} \mathrm{C}$. El segundo paso fue identificación microscópica con coloración de Gram a cada colonia aislada y el aislamiento secundario en dos medios selectivos, Agar Mc Conkey para bacilos gram negativos y Agar TCBS específico para crecimiento del género Vibrio; la incubación fue de 24 horas a $35.5^{\circ} \mathrm{C}$. En este aislamiento se obtuvieron nueve cepas bacterianas puras. A cada una de las nueve cepas se les realizó una 
prueba de identificación bioquímica utilizando el Sistema de pruebas automatizadas BD BBL Crystal. Identification System Enteric/Nonfermenter ID Kit

\section{Selección de cepas bacterianas moderadamente} halófilas

La selección de las cepas moderadamente halófilas, se hizo tomando las nueve cepas bacterianas previamente aisladas y sembrándolas en el medio agar nutritivo con $3 \%$ de cloruro de sodio. El tiempo y temperatura de incubación fue de 24 horas a $37^{\circ} \mathrm{C}$, al cabo de los cuales hubo un crecimiento óptimo de más de 50.000 ufc/100ml en cinco de estas especies; este resultado permitió hacer la selección de los microorganismos para el ensayo. Las cepas se congelaron a $-70^{\circ} \mathrm{C}$ y se conservaron en Agar BAB (agar base sangre Oxoid) hasta iniciar el ensayo. Las cinco cepas bacterianas seleccionadas fueron: Agrobacterium tumefasciens, Flavimonas oryzihabitans, Serratia marcescens, Vibrio alginolyticus y Vibrio metschnikovii.

\section{Preparación de soluciones con sales de sodio para el ensayo}

Las sales utilizadas para el ensayo fueron nitrato de sodio, sulfato de sodio y cloruro de sodio. El criterio que se tuvo para seleccionar estas tres sales, fue su presencia en los suelos salinos y sódicos y el proceso de simulación de las condiciones en las que se encontraría la bacteria con estas sales, si estuviese en ese hábitat. Las concentraciones utilizadas de cada una de las sales fueron $0.05,0.3$ y $0,65 \%$. Las sales fueron diluidas en agua peptonada al $0,1 \%$, medio básico para lograr el crecimiento y desarrollo bacteriano. La peptona utilizada para la preparación de esta agua fue Triptone code L42 de OXOID cuyo constituyente básico, la triptona, es un producto de digestión de la caseína. La cantidad de solución en los tubos en las pruebas preliminares no fue exacta, osciló entre 4,5 y 5,0 $\mathrm{ml}$ aproximadamente. El agua utilizada para la preparación de las soluciones fue destilada, desionizada y esterilizada en autoclave a $121^{\circ} \mathrm{C}$ y $15 \mathrm{lbs}$ de presión por 15 minutos.
Verificación de crecimiento bacteriano en las soluciones con sales de sodio

Las cepas bacterianas seleccionadas se prepararon en concentración de $1.2 \times 10^{8} \mathrm{ufc} / 100 \mathrm{ml}$ en caldo nutritivo. Esta concentración se confirmó por técnicas turbidimetricas y lectura espectrofotométrica. Cada una de las cepas se sembró en tubos que contenían $5 \mathrm{ml}$ del agua peptonada con las tres sales y en las tres concentraciones. La siembra se realizó utilizando 0.1 ul pipeta automática Brand ( 50 - $250 \mathrm{ul}$ ). El tiempo y temperatura de incubación fue de 24 horas y $35.5^{\circ} \mathrm{C}$ al cabo de los cuales se tomo una asada de la solución (0.1ul) y se sembró en agar TCBS, agar sangre y Agar nutritivo con $3 \%$ de cloruro de sodio para verificar si las bacterias se habían desarrollado en el agua peptonada con las sales. El crecimiento fue confirmado después de incubar los medios de cultivo 24 horas a $35.5^{\circ} \mathrm{C}$

\section{Medición de la concentración inicial de sodio en las soluciones.}

Preparación de tubos con agua peptonada y sales de sodio

Se preparó el agua peptonada al $0.1 \%$ en 9 fiolas cada una con una sal de sodio: nitrato de sodio, sulfato de sodio y cloruro de sodio en las concentraciones de $0.05,0.3$ y $0.65 \%$. Se midieron $5 \mathrm{ml}$ de cada una de las soluciones y se colocaron en tubos de 13 x $100 \mathrm{~mm}$ con tapa rosca estéril. De acuerdo con el número de bacterias y previendo tres repeticiones por cada prueba el total de tubos que se prepararon fue de 27 por cada uno de los microorganismos bacterianos seleccionados así: nueve tubos con nitrato de sodio, tres al $0,05 \%$, tres al $0,3 \%$ y tres al $0,65 \%$; nueve tubos con sulfato de sodio, tres al $0,05 \%$, tres al $0,3 \%$ y tres al $0,65 \%$; nueve tubos con cloruro de sodio, tres al $0,05 \%$, tres al $0,3 \%$ y tres al $0,65 \%$;. Una vez depositadas las soluciones en los tubos se procedió a esterilizar en autoclave a $121^{\circ} \mathrm{C}$ y $15 \mathrm{lbs}$ de presión por 15 minutos. 
Medición previa de las concentraciones de sodio.

Las soluciones de agua peptonada con las sales de sodio se llevaron al laboratorio de suelos de la Facultad de Agronomía de la Universidad Nacional para realizar la cuantificación de sodio por espectroscopia de absorción atómica en el equipo Perkin Elmer Analyst 300, el cual posee lámpara de cátodo hueco con argón inerte. Para esta medición fue necesario hacer una dilución 1:10 en agua destilada, y desionizada para lograr la concentración necesaria que el equipo requería para hacer las lecturas correspondientes. Las diluciones fueron preparados en tubos Falcon estériles en los cuales se colocó 1,0 $\mathrm{ml}$ de cada uno de los tubos y se diluyó en 9,0 ml para obtener la dilución 1:10. Se agregaron 5 gotas de Lantano con el fin de evitar interferencia con otros iones.

Inoculación de los microorganismos en las sales de sodio

\section{Preparación, siembra, verificación de crecimiento e identificación bioquímica de los cinco microorganismos bacterianos}

Las cepas bacterianas conservadas a $-70^{\circ} \mathrm{C}$ y en agar base sangre se prepararon para ser utilizadas en el ensayo. Se verificó nuevamente su viabilidad y crecimiento en los medios selectivos Agar Mc Conkey, TCBS y agar nutritivo con $3 \%$ de cloruro de sodio. Se verificó su comportamiento bioquímico utilizando pruebas automatizadas BD BBL Crystal. (Identification System Enteric/Nonfermenter ID Kit.) Se suspendieron en caldo nutritivo en concentración de $1.2 \times 10^{8} \mathrm{ufc} / 100 \mathrm{ml}$.

La siembra de los microorganismos en los tubos de las sales se realizó en Cabina de flujo laminar en condiciones de esterilidad que requiere este procedimiento. Se midió 0.1 ul de la dilución de microorganismos, con pipeta automática Brand (50 - 250 ul) de la suspensión de bacterias en el caldo nutritivo en concentración de $1.2 \mathrm{x}$ $10^{8} \mathrm{ufc} / 100 \mathrm{ml}$ y se inoculó en el agua peptonada al $0.1 \%$ con las soluciones en 27 tubos para cada bacteria. Los tubos se incubaron a $35.5^{\circ} \mathrm{C}$ por 24 horas. Finalizada la incubación, se procedió a confirmar la presencia y viabilidad de los microorganismos en las soluciones y la identificación bioquímica correspondiente. En cabina de flujo laminar, se tomó una asada de cada uno de los tubos incubados y sembró en los medios de cultivo selectivo Agar Mc Conkey, TCBS y agar nutritivo con $3 \%$ de cloruro de sodio. Los medios de cultivo se incubaron a $35.5^{\circ} \mathrm{C}$ por 24 horas y se observó el crecimiento. Confirmado el crecimiento se procedió a realizar identificación bioquímica utilizando pruebas automatizadas BD BBL Crystal. Identification System Enteric/Nonfermenter ID Kit.

\section{Separación de las células bacterianas y obten-} ción del sobrenadante

Una vez confirmado el crecimiento bacteriano, los microorganismos fueron separados para cuantificar nuevamente el sodio en el agua peptonada con las sales de sodio. Este procedimiento se hizo centrifugando cada uno de los tubos a 2500 r.p.m por 20 minutos. El tiempo y las revoluciones utilizadas se obtuvieron comparando una lectura óptica antes y después de la centrifugación en diferentes tiempos y r.p.m hasta encontrar lecturas ópticas similares. Una vez separado el pellet de células bacterianas de todos los tubos del experimento, se procedió a separar con una pipeta automática estéril $1 \mathrm{ml}$ de este sobrenadante y depositarlo en tubos Falcon para realizar nuevamente la dilución 1:10 requerida para la lectura del sodio.

Medición de la concentración final de sodio en los sobrenadantes

Los sobrenadantes obtenidos de las soluciones de agua peptonada con las sales de sodio después de ser sometidos a la inoculación de microorganismos y posterior separación del pellet bacteriano, se llevaron al laboratorio de suelos de la Facultad de Agronomía de la Universidad Nacional para realizar la cuantificación de sodio por espectroscopia de absorción atómica.

Análisis de varianza ANOVA y prueba de Tukey para comparaciones múltiples

La aplicación de diseño experimental para validar el análisis de resultados se hizo utilizando el programa 
Tabla 1. Identificación de las bacterias halófilas aisladas con el sistema automatizado de identificación bioquímica BBL CrystalTM

\begin{tabular}{lll}
\hline Código & $\begin{array}{l}\text { Porcentaje de } \\
\text { confiabilidad (\%) }\end{array}$ & Microorganismo identificado \\
\hline 3243204212 & 97 & Vibrio alginolyticus \\
0241304012 & 99.98 & Vibrio metschnikovii \\
2003100010 & 98.8 & Flavimonas oryzihabitans \\
0321300100 & 92.7 & Agrobacterium tumefasciens \\
0763256117 & 90.75 & Serratia marcescens
\end{tabular}

Los porcentajes de confiabilidad son estadísticas que presenta el software cuando hace la identificación del microorganismo.

estadístico R. Se hicieron análisis de varianza a los resultados iniciales y finales de cada una de las bacterias, a las tres sales utilizadas y a las tres concentraciones. Posteriormente se establecieron comparaciones múltiples entre los datos obtenidos por cada bacteria y se compararon también los datos obtenidos para cada sal y concentración entre las cinco bacterias para establecer si había diferencias significativas.

\section{Resultados}

\section{Ensayos preliminares}

\section{Identificación de cepas bacterianas halófilas}

Las cinco especies bacterianas que demostraron crecimiento óptimo, más de 50.000 ufc/100ml y comportamiento halófilo moderado por crecer en agar nutritivo con 3\% de cloruro de sodio identificadas con el sistema BD BBL Crystal se presentan en la Tabla 1.

Las bacterias halófilas, además de necesitar el agua para su supervivencia, requieren ciertas concentraciones de sodio y por lo tanto el agua de mar provee el ambiente óptimo para su crecimiento y desarrollo; sin embargo, algunos de estos microorganismos han sido encontrados en agua fresca en la cual haya alguna concentración de sodio que haga propicia la vida de estos microorganismos. Prueba de ello, es la muestra de donde fue obtenido uno de los microorganismos incluido en este estudio, Vibrio metschnikovii, aislado de agua superficial de un humedal.
Vibrio alginolyticus y Serratia marcescens fueron aislados de agua de mar; Flavimonas oryzihabitans y Agrobacterium tumefasciens fueron tomadas de agua estancada en un humedal de la Sabana de Bogotá. Aunque Serratia marcescens, Flavimonas oryzihabitans y Agrobacterium tumefasciens no están clasificadas como halófilas, fueron incluidas en el experimento, por cuanto in vitro demostraron crecer en presencia de altas concentraciones de sodio. De acuerdo con este crecimiento todas las bacterias utilizadas en este estudio se consideran halófilas discretas porque crecieron en medios con cloruro de sodio entre 1 y $6 \%$.

\section{Crecimiento en las sales de sodio}

Las bacterias halófilas que se inocularon en la solución peptonada con las sales de sodio en las diferentes concentraciones tuvieron crecimiento óptimo de más de $50.000 \mathrm{ufc} / 100 \mathrm{ml}$ en los medios seleccionados, comprobando su capacidad para crecer en las soluciones y conservar su viabilidad. Esto permite demostrar que las cinco bacterias halófilas utilizadas en el experimento son capaces de crecer en soluciones con iones de sodio en forma de sales.

Las pruebas rápidas de identificación confirmaron la identidad de las bacterias halófilas. Esta primera fase del experimento que correspondió a las pruebas preliminares permitió hacer una selección adecuada de microorganismos desde el punto de vista de comportamiento bioquímico frente a medios sólidos y 
Tabla 2. Medición de la concentración inicial y final de sodio.

\begin{tabular}{|c|c|c|c|c|c|c|c|c|c|c|c|}
\hline \multirow{3}{*}{ Sales } & \multirow{3}{*}{ Concentración } & \multicolumn{10}{|c|}{ Valores de sodio $\mathrm{mg} / \mathrm{l}$} \\
\hline & & \multicolumn{2}{|c|}{$\begin{array}{l}\text { Vibrio } \\
\text { alginolyticus }\end{array}$} & \multicolumn{2}{|c|}{$\begin{array}{l}\text { Vibrio } \\
\text { metschnikovii }\end{array}$} & \multicolumn{2}{|c|}{$\begin{array}{l}\text { Flavimonas } \\
\text { oryzihabitans }\end{array}$} & \multicolumn{2}{|c|}{$\begin{array}{c}\text { Agrobacterium } \\
\text { tumefasciens }\end{array}$} & \multicolumn{2}{|c|}{$\begin{array}{l}\text { Serratia } \\
\text { marcescens }\end{array}$} \\
\hline & & Inicial & Final & Inicial & Final & Inicial & Final & Inicial & Final & Inicial & Final \\
\hline \multirow{9}{*}{$\begin{array}{c}\text { Nitrato } \\
\text { de } \\
\text { sodio }\end{array}$} & \multirow{3}{*}{0,05} & 0,78 & 0,71 & 0,49 & 0,07 & 0,56 & 0,2 & 0,47 & 0,71 & 0,59 & 0,64 \\
\hline & & 0,65 & 0,7 & 0,38 & 0,15 & 0,46 & 0,24 & 0,45 & 0,22 & 0,38 & 0,8 \\
\hline & & 0,59 & 0,43 & 0,55 & 0,09 & 0,41 & 0,63 & 0,59 & 0,27 & 0,54 & 0,56 \\
\hline & \multirow{3}{*}{0,3} & 2,48 & 3,74 & 2,75 & 1,24 & 2,06 & 2,55 & 2,12 & 1,84 & 2,11 & 3,64 \\
\hline & & 2,34 & 2,76 & 2,38 & 0,64 & 2,05 & 4,8 & 2,72 & 5,12 & 2,35 & 3,58 \\
\hline & & 2,59 & 2,46 & 2,56 & 1,57 & 2,11 & 2,75 & 2,12 & 5,01 & 2,11 & 3,73 \\
\hline & \multirow{3}{*}{0,65} & 4,04 & 1,6 & 4,18 & 0,3 & 4,07 & 0,43 & 8,54 & 4,6 & 3,98 & 6,06 \\
\hline & & 4,64 & 1,67 & 4,71 & 0,47 & 3,97 & 4,11 & 3,94 & 4,58 & 3,8 & 5,82 \\
\hline & & 4,47 & 2,65 & 4,1 & 2,29 & 4,09 & 0,27 & 4,06 & 3,11 & 3,98 & 3,18 \\
\hline \multirow{9}{*}{$\begin{array}{c}\text { Sulfato } \\
\text { de } \\
\text { sodio }\end{array}$} & \multirow{3}{*}{0,05} & 0,76 & 0,94 & 0,58 & 0,47 & 0,54 & 0,47 & 0,55 & 0,56 & 0,6 & 0,66 \\
\hline & & 0,82 & 0,32 & 0,57 & 0,28 & 0,57 & 0,56 & 0,63 & 0,93 & 0,52 & 0,96 \\
\hline & & 0,6 & 0,36 & 0,54 & 0,28 & 0,55 & 0,46 & 0,64 & 0,8 & 0,86 & 0,85 \\
\hline & \multirow{3}{*}{0,3} & 2,31 & 1,7 & 2,8 & 0,88 & 2,33 & 3,13 & 2,53 & 1,17 & 2,25 & 3,26 \\
\hline & & 2,31 & 1,96 & 2,12 & 0,8 & 2,29 & 2,36 & 2,43 & 1,53 & 2,2 & 3,4 \\
\hline & & 2,24 & 1,8 & 3,06 & 0,67 & 2,11 & 5,02 & 2,64 & 1,6 & 2,77 & 3,82 \\
\hline & \multirow{3}{*}{0,65} & 4,98 & 2,84 & 4,6 & 2,04 & 4,87 & 3,9 & 4,49 & 0,33 & 4,88 & 6,14 \\
\hline & & 5,1 & 2,55 & 4,76 & 3,79 & 5,18 & 3,3 & 4,95 & 0,47 & 4,38 & 5,96 \\
\hline & & 5,45 & 3,25 & 5,39 & 0,2 & 4,48 & 3,96 & 4,93 & 0,35 & 5,09 & 5,93 \\
\hline \multirow{9}{*}{$\begin{array}{c}\text { Cloruro } \\
\text { de } \\
\text { sodio }\end{array}$} & \multirow{3}{*}{0,05} & 0,82 & 1,21 & 0,82 & 0,64 & 0,78 & 0,68 & 0,68 & 1,46 & 0,86 & 3,02 \\
\hline & & 1,12 & 0,98 & 0,77 & 0,37 & 0,85 & 0,57 & 0,96 & 1,28 & 1,3 & 2,95 \\
\hline & & 0,96 & 1,16 & 0,96 & 0,54 & 1,02 & 1,17 & 0,77 & 1,34 & 0,92 & 3,57 \\
\hline & \multirow{3}{*}{0,3} & 3,16 & 2,78 & 2,74 & 2,29 & 3,94 & 4,5 & 3,04 & 4,73 & 2,63 & 4,09 \\
\hline & & 3,52 & 3,32 & 2,6 & 1,32 & 3,2 & 3,73 & 2,66 & 3,21 & 2,64 & 5,28 \\
\hline & & 3,05 & 2,96 & 2,8 & 1,95 & 3,47 & 3,99 & 2,62 & 2,45 & 2,45 & 3,03 \\
\hline & \multirow{3}{*}{0,65} & 6,59 & 6,14 & 5,31 & 5,14 & 6,02 & 7,58 & 4,4 & 5,84 & 5,48 & 11,63 \\
\hline & & 5,96 & 4,9 & 5,67 & 3,94 & 5,88 & 8,58 & 4,96 & 5,11 & 5,56 & 9,28 \\
\hline & & 5,65 & 5,26 & 4,47 & 3,8 & 5,74 & 3,12 & 5,08 & 5,19 & 6,06 & 8,66 \\
\hline
\end{tabular}

líquidos y además verificar que si podían crecer sin utilizar prácticamente nutrientes.

\section{Medición de la concentración inicial de sodio}

Los datos obtenidos en la cuantificación inicial de sodio variaron de acuerdo con la concentración. La lectura arrojada por el equipo de absorción atómica permite ver que los valores de sodio son directamente proporcionales a la concentración de sodio presente en las tres sales en las cinco bacterias, Tabla 2. 
Verificación de crecimiento bacteriano e identificación bioquímica de las cinco bacterias

La totalidad de las muestras tomadas crecieron en los medios seleccionados. La identificación se hizo con pruebas rápidas de identificación y el resultado permitió establecer que las bacterias seleccionadas e inoculadas no cambiaron su comportamiento bioquímico y no se contaminaron con otros microorganismos en el transcurso del ensayo. Los resultados obtenidos permiten afirmar que los microorganismos se desarrollaron adecuadamente en los medios con sales de sodio y la identificación y confirmación de la pureza de las bacterias que inicialmente se habían inoculado se mantuvo. Las características bioquímicas y comportamiento en los medios fue la misma que al iniciar la prueba; esto significa que las sales no generan ningún cambio fenotípico importante.

\section{Medición de la concentración final de sodio en} los sobrenadantes

Los datos obtenidos en esta medición se presentan junto con los obtenidos en la medición de la concentración inicial, Tabla 2. Los resultados obtenidos en los sobrenadantes, la comparación con las concentraciones iniciales de sodio y la aplicación del análisis estadístico dan respuesta a los objetivos planteados en este experimento, en particular a la verificación de la captura de iones sodio por parte de bacterias halófilas. En esta investigación el término bacterias halófilas fue asignado a los microorganismos que crecieron en un medio sólido con una concentración de cloruro de sodio al 3\%. Sin embargo, es importante hacer algunas observaciones. Por una parte, es diferente que una bacteria crezca en un medio sólido o líquido y se considere halófila por tener esta propiedad y otra es que esa propiedad le permita capturar los iones sodio. Solamente con la cuantificación de sodio en esta fase, se pudo determinar si las bacterias halófilas eran o no capaces de tomar el sodio in vitro.

La capacidad halófila de un microorganismo no debería medirse por crecer o no en un medio con una determinada concentración de sal de sodio, sino que debe ser medida por su actividad bioquímica en la cual utiliza el sodio para sus procesos esenciales de supervivencia y desarrollo. Los resultados obtenidos en esta investigación así lo demuestran con el comportamiento que tuvo la bacteria Serratia marcescens, que toleró un nivel alto de sodio pero que no capturo los iones, lo que hace pensar que tiene mecanismos enzimáticos con lo cuales tolera la presión osmótica que genera la presencia de este ión. Aunque este presupuesto teórico sobre cómo las bacterias utilizan el sodio no hace parte de los objetivos de esta investigación, es evidente que muchos de estos procesos aún no son bien conocidos y será necesario considerar otras investigaciones para verificar esta afirmación.

\section{Análisis estadístico}

La aplicación de diseño experimental manejando análisis de varianza y comparaciones múltiples con la prueba de Tukey, permitió establecer la captura de iones por cada una de las bacterias, la diferencia de captura en cada una de las sales y el comportamiento en las tres concentraciones, así como las bacterias más eficientes para la captura del sodio. Los resultados que permitieron dar respuesta a los objetivos de esta investigación se relacionan a continuación: la captura de sodio in vitro fue realizada en forma eficiente por las dos bacterias halófilas del género Vibrio utilizadas en el experimento como lo demuestran los datos arrojados por el programa R; Flavimonas oryzihabitans y Agrobacterium tumefasciens que se comportaron como halófilas en las pruebas preliminares, presentaron variaciones significativas en la captura de los iones sodio que se evidencian en los resultados arrojados por ANOVA y las pruebas de comparación múltiple aplicadas a estos microorganismos; los resultados de Serratia marcescens confirman su incapacidad para capturar sodio in vitro.

En la Figura 1 se observan los datos de Vibrio alginolyticus, y en ella se evidencia que la concentración de los iones sodio son menores que los iniciales en la mayoría de las concentraciones y sales, lo que permite afirmar que esta bacteria si es capaz de capturar iones sodio. 
Nitrato de sodio

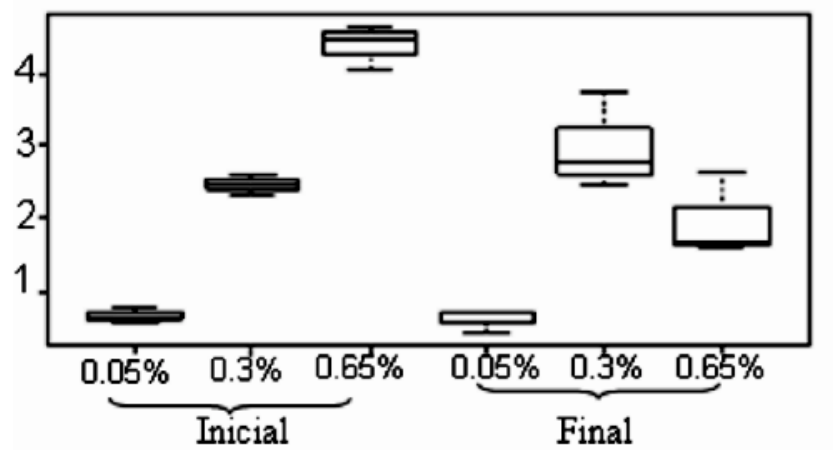

Sulfato de sodio

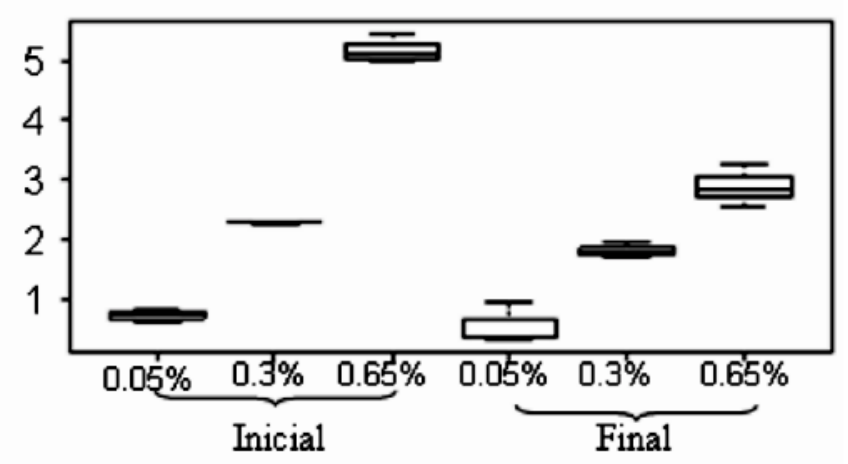

Cloruro de sodio

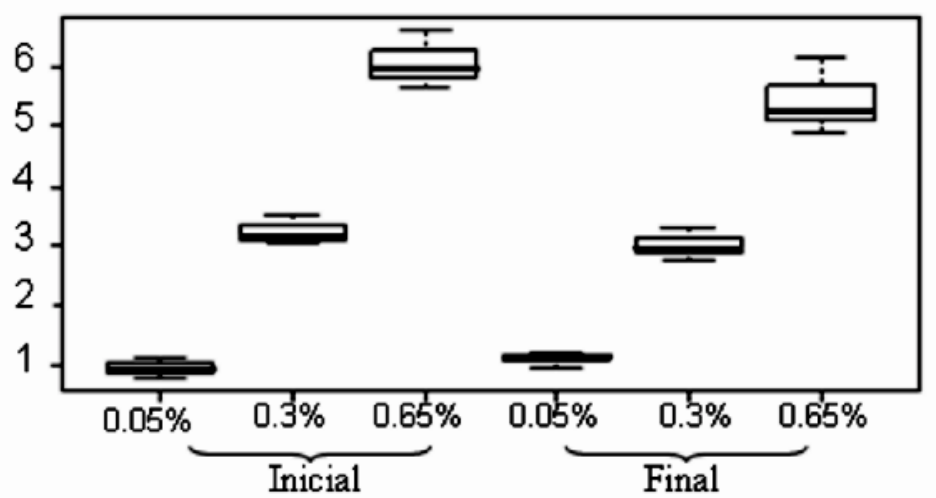

Figura 1. Resultados en diagramas de caja de la concentración de sodio inicial y final en las tres sales y las tres concentraciones para Vibrio alginolyticus
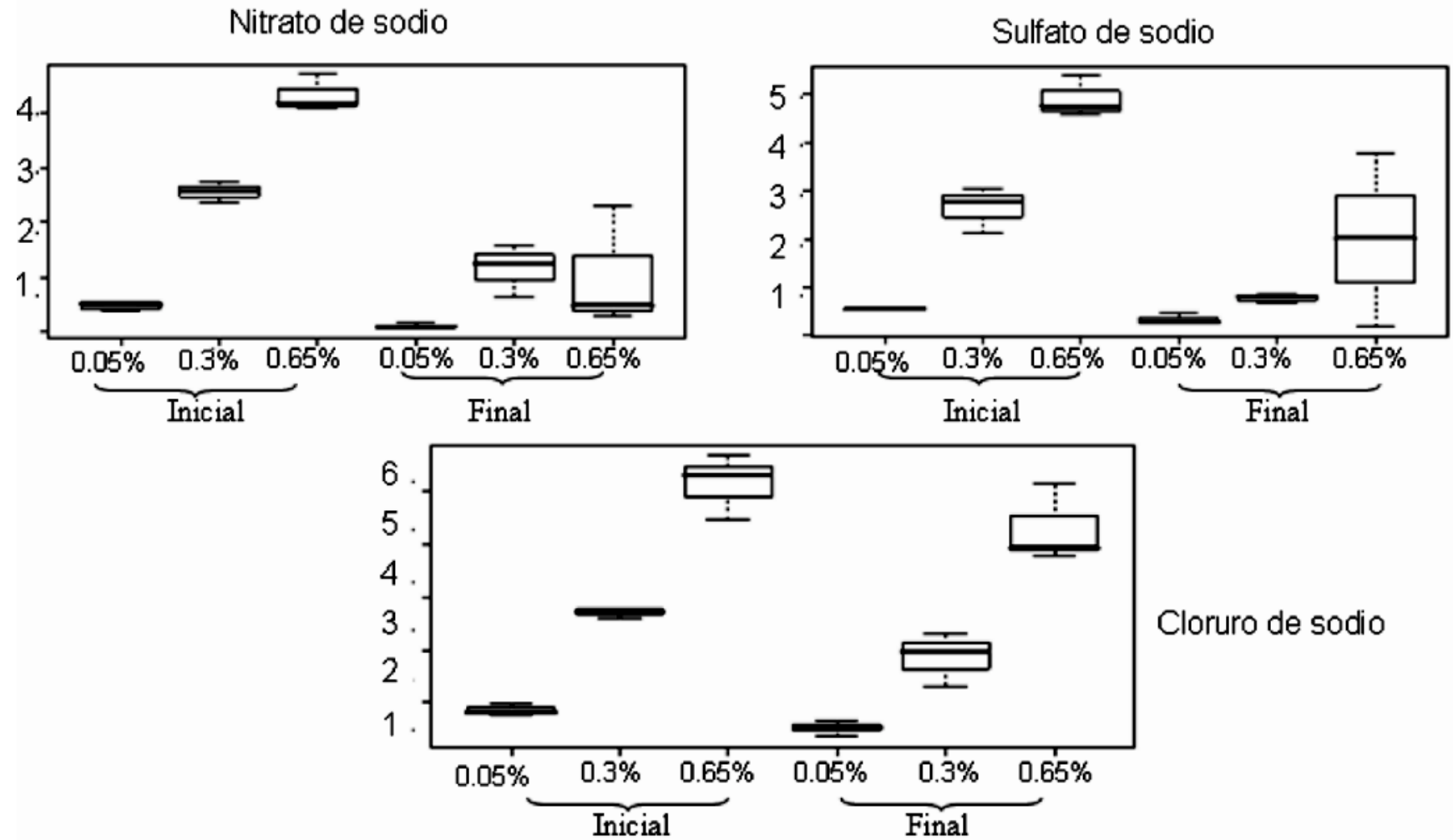

Cloruro de sodio

Figura 2. Resultados en diagramas de caja de la concentración de sodio inicial y final en las tres sales y las tres concentraciones para Vibrio metschnikovii 
La Figura 2 revela el comportamiento de Vibrio metschnikovii. Se observa que en todos los casos hay disminución de los niveles de sodio final lo que indica la capacidad de captura de iones sodio que tiene esta especie. Vibrio metschnikovii es un microorganismo que no ha sido reportado como patógeno sino en personas con el sistema inmunológico suprimido. Algunas investigaciones lo han encontrado con otros microorganismos en desórdenes gastrointestinales, pero aún no se sabe si su patogenicidad es particular o por estar asociada con otros microorganismos. Su hábitat es más variado, puede estar en agua de mar pero también ha sido encontrado en humedales y sus requerimientos de sodio son mucho más altos que los de Vibrio alginolyticus (11)

Una comparación entre los resultados obtenidos con Vibrio metschnikovii y Vibrio alginolyticus permitieron ver que la captura de sodio fue más eficiente con $V$. metschnikovii. Se pudo observar también que no hubo preferencia por ninguna de las sales y tampoco por alguna concentración en particular aunque se observó mayor variabilidad a medida que aumentó el porcentaje de sodio.

La capacidad que tiene el género Vibrio para tomar el sodio está determinada por la forma en que utiliza el sodio para varias de sus funciones esenciales. Vibrio alginolyticus contiene una quinona reductasa dependiente de NADH-quinone reductase (NQR) enzima ubicada en la transmembrana y compuesta por seis unidades que está encargada de la cadena respiratoria y que funciona con una bomba de sodio electrogénica., la cual está compuesta por una bomba de sodio primaria, seguida de una bomba de hidrogeno y de Sodio/hidrogeno. El potencial electroquímico dado por el gradiente de sodio, participa también en la rotación de flagelos y es la fuerza motora para la toma activa de todos los aminoácidos, actividad metabólica esencial para su crecimiento y desarrollo (12-17).

Las bacterias han desarrollado sistemas para incorporar nutrientes que incluso funcionan en contra del gradiente de concentración (18). Para ello, utilizan las permeasas, proteínas de transporte ubicadas en las membranas que funcionan de acuerdo a la concentración de nutrientes en el medio y de acuerdo a las necesidades metabólicas de cada microorganismo. Se han identificado dos sistemas de transporte: el cotransporte paralelo o Symport en la cual se utiliza el $\mathrm{H}+\mathrm{u}$ otro ión (en el caso de Vibrio específicamente es el $\mathrm{Na}+$ ) unido directamente a una molécula nutritiva, glucosa o un aminoácido. El movimiento del ión a través de la membrana se hace a favor de un gradiente de concentración y obligatoriamente la otra molécula será transportada en contra del gradiente de concentración. El otro sistema es la fosforilación del azúcar como parte del mecanismo de incorporación, lo que genera una elevación del $\mathrm{H}+$ en el interior de la célula y por lo tanto un proceso de cotransporte antiparalelo en el cual se extraen los protones formados durante el metabolismo; de esta manera el pH del medio externo en el que esta la bacteria puede llegar hasta 5.0 o 5.5 y el citoplasma tendrá aproximadamente un $\mathrm{pH}$ de 7.3 , lo que le permite al microorganismo mantenerse detoxificado y estable $(11,19)$

En la Figura 3 se observa como Flavimonas oryzihabitans capturó iones en la solución de nitrato de sodio en las concentraciones de $0.05 \%$ y $0.65 \%$, en la solución de sulfato de sodio en las concentraciones de $0.05 \%$ y $0.65 \%$; en la solución con cloruro de sodio capturó iones en la concentración de $0.05 \%$.

Flavimonas oryzihabitans se convierte en una posibilidad interesante para capturar iones sodio. Esta bacteria está reportada como patógena oportunista para el hombre en casos de inmunosupresión pero en condiciones normales la bacteria es saprofítica; es una bacteria que se adapta a varios hábitats y esta podría ser una ventaja frente a Vibrio que ha sido reportada en hábitats exclusivamente acuáticos.

En la Figura 4 se observa que Agrobacterium tumefasciens capturó iones sodio solamente en sulfato de sodio en todas las concentraciones pero no captura sodio en nitrato de sodio y en cloruro de sodio. Agrobacterium tumefasciens es una bacteria reportada como fitopatógena, sin embargo es la bacteria utilizada para transformación genética por excelencia y de ella se conoce muy bien su comportamiento bioquímico y 
Nitrato de sodio

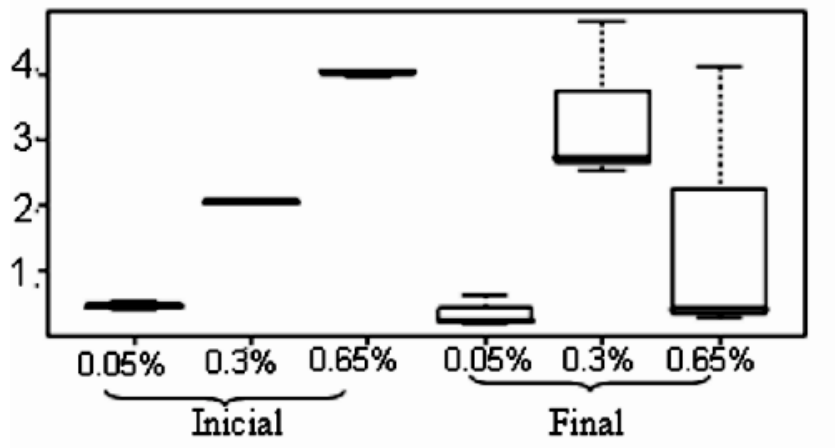

Sulfato de sodio

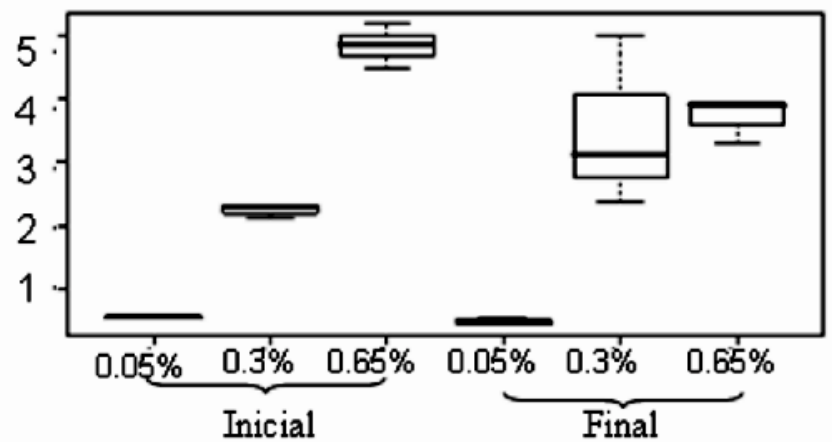

Inicial

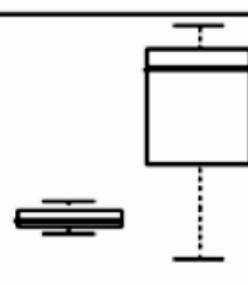

Cloruro de sodio

Figura 3 Resultados en diagramas de caja de la concentración de sodio inicial y final en las tres sales y las tres concentraciones para Flavimonas oryzihabitans

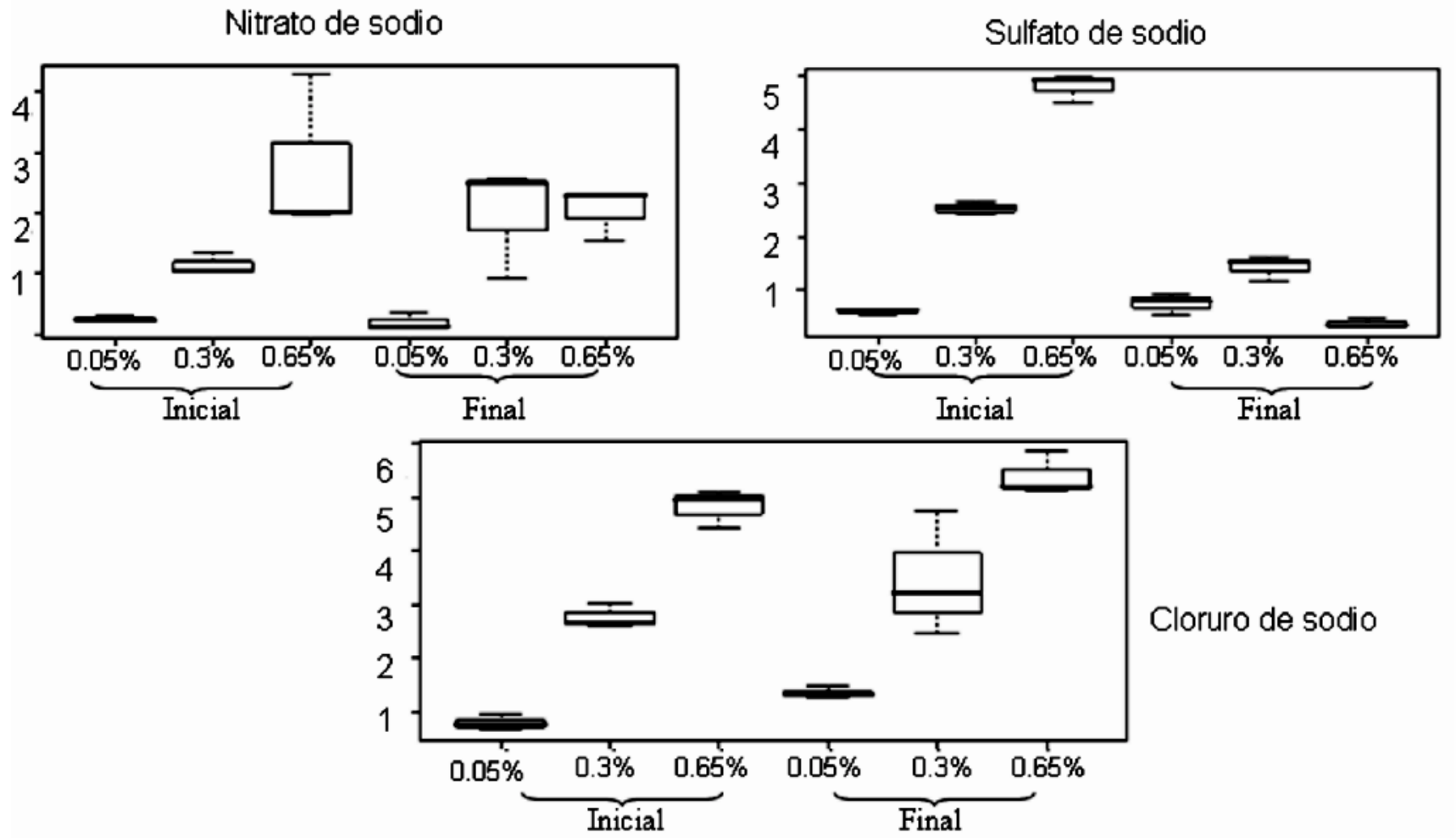

Figura 4. Resultados en diagramas de caja de la concentración de sodio inicial y final en las tres sales y las tres concentraciones para Agrobacterium tumefasciens 
Nitrato de sodio

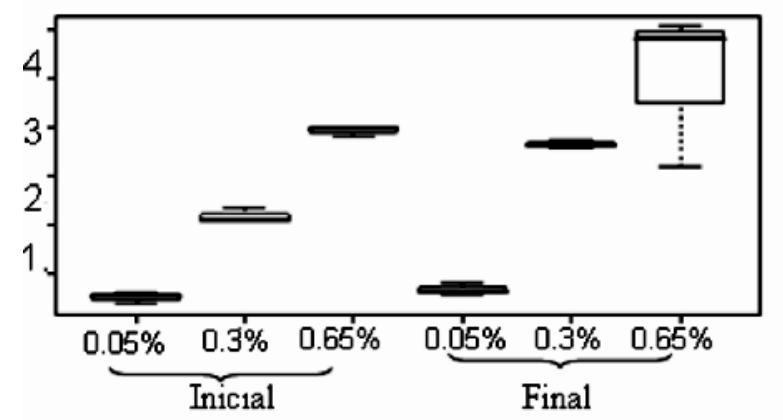

Sulfato de sodio

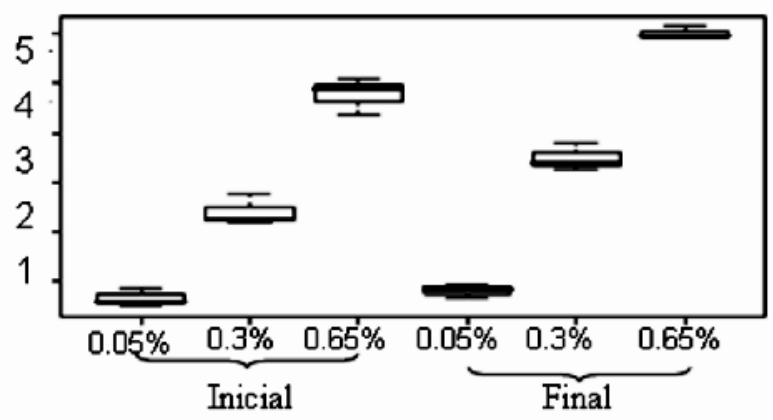

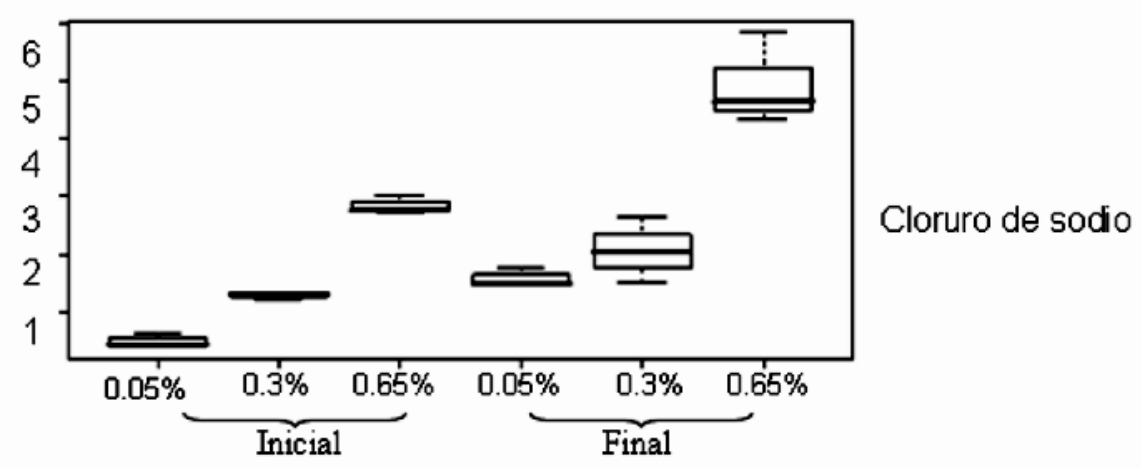

Figura 5. Resultados en diagramas de caja de la concentración de sodio inicial y final en las tres sales y las tres concentraciones para Serratia marcescens

condiciones genotípicas (20). No ha sido reportada como halófila, pero posiblemente por ser su hábitat el suelo le permita adaptarse a una condición edáfica de salinidad y sodicidad. Esta bacteria goza de algunas ventajas sobre Flavimonas oryzihabitans y aunque la captura de iones sodio solo se hizo con sulfato de sodio, debido a la adaptabilidad y facilidad de ser utilizada en ingeniería genética podría ser una alternativa para insertar genes de bombas de sodio de otras bacterias para mejorar esta actividad o inducir la capacidad de captura con otras sales.

En la Figura 5 se observa el comportamiento de Serratia marcescens como una bacteria incapaz de capturar iones sodio in vitro puesto que las concentraciones de sodio en la lectura final siempre fueron más altas que en las concentraciones iniciales.

La variabilidad que presentaron algunos resultados pudo corresponder a errores cometidos en el procedimiento de medición de la sal en los tubos, a pérdida de agua en el procedimiento de transporte o de manipulación al realizar las diluciones para hacer las lecturas de sodio. Otra explicación a esta variabilidad pudo ser que la medida de la cuantificación en el espectrofotómetro de absorción atómica se hace en partes por millón p.p.m. y por ser una medida tan pequeña puede generar márgenes de error cuando se utilizan concentraciones altas del ión a analizar. La comprobación de la captura de sodio por cuatro de las bacterias utilizadas en el experimento abre la posibilidad de pensar en una alternativa biológica de remediación de suelos utilizando microorganismos. La diferencia de resultados obtenida por las cuatro especies más que ser un problema, es una ventaja, por cuanto se pueden pensar diferentes alternativas para plantear los procesos de bioremediación.

Un planteamiento previo es considerar cual bacteria utilizar, si la que mejor se comportó capturando los iones o la que tuvo un comportamiento aceptable pero tiene otras características que la hacen una mejor candidata. en el caso de las dos especies de Vibrio, habría que analizar sus desventajas: primero, esta especie se ha desarrollado siempre en hábitats acuáticos y por lo tanto no se puede saber si al colocarlo en el suelo, va a sobrevivir; segundo, muchas de estas especies son patógenas para el hombre. Flavimonas oryzihabitans, por otra parte, presentó también una buena capacidad 
de captura de sodio in vitro y sus características la hacen una opción viable, si se trata de establecer un microorganismo en un hábitat diferente porque ella se encuentra en suelo o agua. Pero la variabilidad hace tomar como primera opción la especie Vibrio.

En el caso de Vibrio el problema que concierne a la patogenicidad para el hombre puede obviarse utilizando especies que no hayan sido reportadas como patógenas en el hombre y que toleren altas cantidades de sodio para inocularlas en el suelo; esto implicaría someter las especies seleccionadas a los procedimientos establecidos en esta investigación, verificar que puedan resistir el hábitat y diseñar un procedimiento para confirmar que estos microorganismos no nativos si pudieron ejercer su función de captura de sodio in situ. En caso de usar Vibrio o Flavimonas oryzihabitans es necesario resolver otro problema: como comprobar que la bacteria inoculada ha capturado los iones sodio.

Los procesos de bioremediación están orientados en primer lugar a no generar impacto ambiental y esto implica que se debe utilizar la flora nativa del suelo en el cual se quiere realizar el proceso de bioremediación. Por lo tanto, la solución no estaría en el ingreso o implantación de un microorganismo sino en reforzar o introducir las táctica bioquímicas de la bacteria con la capacidad de captura de iones sodio en los microorganismos nativos que conforman el suelo. Sin embargo, en el caso de suelos salinos y sódicos las condiciones mismas del suelo son críticas y por lo tanto los consorcios microbianos nativos están reducidos por las condiciones tan adversas que genera la presencia de las sales y por otra el $\mathrm{pH}$ alcalino que tienen los suelos por la presencia de sales en especial el bicarbonato.

La primera propuesta para utilizar los resultados de esta investigación es diseñar un bioreactor con un consorcio microbiano que incluya las bacterias que capturaron sodio en el experimento e incluir microorganismos que sean capaces de capturar los iones sodio de las sales que al parecer, algunas de las bacterias no pudieron utilizar como se vio en los resultados con Agrobacterium tumefasciens. La utilización de un bioreactor permitiría la transformación de los contaminantes y posteriormente el retiro de los mismos de ese terreno lo que garantizaría la recuperación de ese suelo porque ya no tiene el elemento que le generó el problema. La ventaja de esta propuesta es que al diseñar este bioreactor, podrían utilizarse las bacterias que no son nativas del suelo y que evidenciaron la captura de los iones sodio in vitro sin importar si son patógenas o no para el hombre porque tan solo estarán cumpliendo esta función y no van a quedar se en el suelo. La mayor ventaja de utilizar esta alternativa es minimizar el impacto ambiental.

La segunda propuesta está orientada a la utilización de ingeniería genética. Esta alternativa aunque costosa puede tener buenos resultados. En esta propuesta se deben considerar dos opciones: una, sería obtener la información sobre la flora nativa existente en los suelos salinos y sódicos y pensar en realizar una implantación del gen de bomba de sodio de la especie Vibrio a estas especies nativas. Pero el problema que surge, es que solamente se conoce la identidad del $1 \%$ de la comunidad microbiana existente en un suelo en buenas condiciones. La otra opción es hacer plásmidos con el gen de la bomba de sodio e implantarlos en una o más especies de la comunidad microbiana existente en la capa inmediatamente inferior a la costra que se forma en los suelos sódicos.

Cualquiera que sea la propuesta, no se debe olvidar que de ser exitosa, debe aplicarse simultáneamente con procedimientos químicos y culturales conocidos, para la recuperación de los suelos salinos y sódicos; además, se debe establecer un equipo interdisciplinario en el cual se vea en forma conjunta la solución más viable e integral para resolver el problema. Los resultados obtenidos en esta investigación solo constituyen un aporte y el primer paso para tratar de recuperar suelos que han dejado de ser productivos por ser salinos y sódicos.

\section{Agradecimientos}

La investigadora presenta agradecimientos al Doctor Heliodoro Arguello por su dirección y apoyo incondicional; al equipo humano del Laboratorio de suelos y aguas de la Facultad de Agronomía de la Universidad 
Nacional de Colombia; a las directivas de la Universidad Colegio Mayor de Cundinamarca; a los compañeros de trabajo, estudiantes y amigos por sus aportes académicos, científicos y logísticos para el desarrollo del proyecto.

\section{Referencias}

1. Oldeman, L. R. Global extent of soil degradation. International Soil Reference and Information Centre. Hinkeloord Agricultural University Wageningen, 1991.

2. Brandt, C. J.; Thornes, J. B. Mediterranean Desertification and Land Use. John Wiley \& Sons, Chichester, 1996. pp. 43-86.

3. FAO. Global Network on Integrated Soil Management for Sustainable Use of Salt-Affected Soils. Food and Agriculture Organization, Rome, Italy 2000.

4. FAO. The Salt of the Earth: Hazardous for Food Production. World Food Summit, Food and Agriculture Organization, Rome, Italy 2002.

5. Sanchez, P.A.; Cochrane, T.T. Soil constrains in relation to major farming systems of Tropical America. In Soil related constrain to food production in the tropics. Los Baños, Filipinas, 1980, pp. 107-139.

6. Aguilera, M.F. El problema de la salinidad y sodio en el Valle del Cauca. Suelos Ecuatoriales. Colombia. 1979, 10 (2): 98 - 114.

7. Eweis, Juana., Ergas Sarina., Chang Daniel., Schroeder Edward. Principios de recuperación. Editorial Mc Graw Hill. España. 1999.

8. Chen Bor-Yann., Wu Chih-Hui., Chang Jo-Shu. An assessment of the toxicity of metals to Pseudomonas aeruginosa PU21. Bioresource Technology. 2006,Vol 97. 15: 1880-1886

9. Green-Ruiz Carlos. Mercury(II) removal from aqueous solutions by nonviable Bacillus sp. from a tropical estuary. Bioresource Technology. 2006, Vol 97, 15:1907-1911.
10. Pal Arundhati., Ghosh Suchhanda., Paul A.K. Biosorption of cobalt by fungi from serpentine soil of Andaman. Bioresource Technology. 2005.

11. Madigan Michael., Martinko John., Parker Jack. Brock. Biología de los microorganismos. Pearson Prentice Hall . Madrid. 2004, pp 100-111.

12. Fukuoka Hajime., Yakushi Toshiharu., Kusumoto Akiko., Homma Michio. Assembly of Motor Proteins, PomA and PomB, in the NaC-driven Stator of the Flagellar Motor. J. Mol. Biol. 2005, 351: 707-717.

13. Hayashi Maki., Shibata Naoaki., Nakayama Yuji., Yoshikawa Kazuhiro., Unemotoa Tsutomu. Korormicin insensitivity in Vibrio alginolyticus is correlated with a single point mutation of Gly-140 in the NqrB subunit of the Na+-translocating NADH-quinone reductase. Archives of Biochemistry and Biophysics. 2002, 401: 173-177.

14. Glynn Ian M. Hundred years of sodium pumping. Annu. Rev. Physiol. 2001, 64:1-18.

15. Nakayama Yuji., ayashi Maki.,Unemoto Tsutomu. Identification of six subunits constituting Na.-translocating NADH-quinone reductase from the marine Vibrio alginolyticus Federation of European Biochemical Societies FEBS Letters. 1998, 422: 240.

16. Rosen Barry P. Recent advances in bacterial ion transport. Ann. Rev. Microbiol. 1986. 40:263-86.

17. Bogachev Alexander V., Murtazina Rachilya A., Skulachev Vladimir P. 1997. The Na/e stoichiometry of the Na.-motive NADH : quinine oxidoreductase in Vibrio alginolyticus. FEBS Letters 409: 475-477.

18. Darnell James., Lodish Harvey., Baltimore David. Transporte a través de membranes celulares. En: Biología celular y molecular. Editorial Labor. USA. 1986.

19. Murray Robert., Granner Daryl., Mayer Peter., Rodwell Victor. Harper-Bioquímica. Mexico. 2001, pp. 605-606.

20. Baron Christian. From bioremediation to biowarfare: on the impact and mechanism of type IV secretion systems. FEM Microbiology letters. 2005, 253: 163-170. 